J. Lake Sci. (湖泊科学) , 2014, 26(5):671-681

http://www. jlakes. org. E-mail : jlakes@niglas.ac.cn

(c) 2014 by Journal of Lake Sciences

\title{
江湖连通方案的最佳引水流量研究——以湖北磁湖为例
}

刘佳明, 张艳军, 宋星原, 袁 迪, 舒彩文, 张素琼, 邹 霞

(武汉大学水资源与水电工程科学国家重点实验室,武汉 430072)

摘 要: 江湖连通工程能够在短期内达到改善湖泊水质的目的,在国内外得到了广泛应用. 但是,在保证改善效果的前提 下, 如何尽量节约投资和运行费用、确定合理的引水流量尚未得到充分的研究. 以水环境质量改善后降低的污水处理费 用作为工程经济效益指标, 提出了成本和效益评估方法用以评估计算引水流量与工程经济效益、工程运行成本、净效益 的定量关系, 最后分析得到合理的引水流量范围和最佳引水流量, 并利用基于 DEM 的二维水量水质数学模型来模拟分析 水质改善效果. 该方法应用于湖北黄石磁湖,在其水体连通方案的基础上,模拟 8 种不同引水流量工况, 分析引水流量与 净效益的关系曲线,计算得到最佳引水流量. 结果表明: 随着引水流量的增加,净效益先增大后减小,每次引水的净效益 最大值为 4.05 万元, 相对应的最佳引水流量为 $10.62 \mathrm{~m}^{3} / \mathrm{s}$. 本研究为磁湖及其它类似水域的水污染治理和成本控制提供 了科学的参考依据.

关键词: 引水调控;最佳引水流量;水量水质模型;磁湖

\section{Optimal discharge of pollution flushing in an interconnected river-lake network: A case study of Lake Cihu, Hubei Province}

LIU Jiaming, ZHANG Yanjun, SONG Xingyuan, YUAN Di, SHU Caiwen, ZHANG Suqiong \& ZOU Xia ( State Key Laboratory of Water Resources and Hydropower Engineering Science, Wuhan University, Wuhan 430072, P. R. China)

\begin{abstract}
Interconnections of rivers and lakes, which can improve short-term water qualities in lakes, have been widely used in China. It is necessary to search for the reasonable discharge of pollution flushing in order to achieve the best flushing effect as well as the lowest cost. In this paper, the water environmental improvement effect of different flushing discharges is analyzed, using the two-dimensional water quality mathematical model based on DEM. Furthermore, the cost and benefit evaluation method is put forward to find the quantitative relation between pollution flushing discharges and project benefits. Based upon the Lake Cihu project, the pollution flushing discharges and project benefits curve has been obtained by simulating eight different flushing conditions. The results indicate that with the increase of pollution flushing discharge, the benefit first increases and then decreases, while the maximum benefit is about $¥ 40500$, and corresponds to an optimal pollution flushing discharge of $10.62 \mathrm{~m}^{3} / \mathrm{s}$. This study could provide scientific basis for pollution control and cost control in Lake Cihu and other similar lakes with the river-lake interconnection systems.
\end{abstract}

Keywords: Pollution flushing; the optimal pollution flushing discharge; hydrodynamic and transport model; Lake Cihu

湖泊作为一种与人类生存和发展密切相关的独特资源,在供水、防洪、航运、养殖、旅游及维系区域生态 平衡方面发挥着巨大作用. 目前由于流域的超强度开发和湖泊资源的超强度利用,造成了水环境恶化、水资 源短缺、水灾害频发等一系列问题. 据水利部水文局公布的调查报告 ${ }^{[1]}, 2003$ 年对全国 52 个湖泊进行水质 评价, 26 个湖泊水污染严重, 5 个湖泊部分水体受到污染,水质达标的湖泊不到 $42 \%$, 我国湖泊水污染情况 十分严重. 由于日趋严重的湖泊水环境恶化问题正严重制约着社会和经济的可持续发展,在过去几十年中, 各级政府投人了大量的人力和物力来探索治理和改善湖泊水环境的方法.

时下, 国内外比较有效的手段是引水调控, 即通过引调邻近水域的清水到受污染水体流域来冲刷稀释

* 水利部公益性行业科研专项项目(201101062) 和国家自然科学基金项目 $(51079099,51279140,51209162)$ 联合资 助. 2013-09-25 收稿;2013-12-26 收修改稿. 刘佳明(1990 ), 男, 博士研究生;E-mail:liujmxxx@ 126. com. 
水体中污染物的浓度, 以达到改善水体水环境的目的. 由于其见效快, 引水调控的方法被世界很多地方所采 纳,而且积累了不少经验. 在荷兰, 1979 年通过实施引水换水工程使得 Veluwe 湖 ${ }^{[2]}$ 的水质得到了较明显的 改善, 美国的 Green 湖、Snake 湖等 ${ }^{[3]}$ 均具有相同效果. 在中国, 由于湖泊严重的水体水质污染, 引水较为普 遍. 较早进行引水工程的是杭州西湖, 1968 年朱政军等 ${ }^{[4]}$ 研究发现引水后西湖的总磷浓度下降明显, 总体水 质得到改善. 2002 年开始对太湖开展 “引江济太”工程, 即从附近的长江引水到太湖冲污, 以改善水质和水 华发生的状况, 马巍等 ${ }^{[5]}$ 对该工程的研究结果表明, 引水后 $\mathrm{COD}_{\mathrm{Mn}}$ 等多种水质指标的浓度都随着冲水流量 的增大而减小. 此后, 桂林的 “两江四湖” 工程、武汉的 “大东湖连通” 工程和 “引江济巢” 工程等蓬勃兴起,水 利部也指出 “河湖连通是提高水资源配置能力的重要途径”, 是国家新形势下的一种治水方案, 它不仅可以 有效改善生态环境质量状况, 还可以提高水资源统筹调配能力和增强抵御水旱灾害能力 ${ }^{[9]}$, 因此, 引水调控 在国内得到了广泛应用.

目前大多数相关研究集中在引水后水体水质的改善效果认定上, 以确定水体连通对于改善大范围的水 污染是有效的 ${ }^{[4-8]}$, 但如何使水体连通方案的规模更加合理、引水流量的设计更加科学, 给政府提供具有科 学依据的工程经济效益数据, 合理地节约投资和运行费用, 尚未得到充分研究. 对于江湖连通方案的最佳引 水流量研究,水环境改善的效益进行量化是其重要内容, 也是该领域的前沿问题之一 ${ }^{[10]}$. 目前水利工程经济 效益常用的评价方法有支付意愿法 ${ }^{[11]}$ 、污染损失法 ${ }^{[12]}$ 、影子价格法、等效代替法、资产价值法 ${ }^{[13]}$ 等, 由于引 水工程属于社会公益工程, 其经济和环保价值难以量化,因此这些方法并不完全适用于引水调控工程.

鉴于此,吴浩云等 ${ }^{[14]}$ 运用综合指数法和价值估算法借助水厂效益评估了“引江济太”工程的综合效益. 骆辉煌等 ${ }^{[15]}$ 认为引水调控工程产生的经济效益主要体现在水资源量变化和水环境质量变化产生的效益这 两个方面, 同时提出了基于水污染损失计算模型的引水调控工程经济效益评估初步框架; 杨桐鹤等 ${ }^{[10]}$ 在 “引江济太”工程中应用了这个框架. 通过对比和分析上述的水环境改善效果评价方法和结果可以发现, 这 些方法存在着 3 个问题: 1 ) 需要领域众多的实际数据或信息来支撑, 而这些数据或信息公开度不足、可获性 低或者可靠性较低;2) 很多参数都是通过估算获得, 而且量化过程中选取的计量分项也不同, 使得计算结果 容易受到主观性的影响;3) 没有与水利、环保部门的日常运行维护的费用和机构建立联系, 使得这些方法可 操作性低, 且难以得到公认. 以上 3 个问题导致在实际工程应用中, 这些方法难以准确地评价引水调控工程 的水环境改善效益.

本文旨在研究不同引水流量对湖泊水质改善效果的影响, 考虑到基础数据的可获性和结果的直观性, 选取水环境质量改善后政府降低的污水处理费用作为引水工程经济效益指标. 通过基于 DEM 的二维水量 水质数学模型模拟不同的引水流量工况, 运用文中提出的成本与效益评估方法计算得到引水流量与经济效 益值、运行成本和净效益的定量关系, 从而进一步得到最佳引水流量以及在经济上可行的引水流量范围, 试 图解决引水调控工程中的经济效益问题, 为湖泊的水污染治理提供可靠的科学依据. 以湖北黄石磁湖为例, 在前期规划的磁湖水体连通方案的基础上,阐述了该方法在湖泊的具体应用.

此外, 特别值得注意的是, 许多研究者认为: 引水调控是一个治标不治本的方法 ${ }^{[3]}$, 因为它仅仅只是污 染物的转移,并没有彻底消除污染物. 污染源控制固然是水污染治理的治本之策, 但是污染源的有效控制却 受到技术、经济和社会发展条件的制约, 需要一个较长的时间过程. 面对我国水污染治理刻不容缓的严峻形 势, 可以适当通过引水调控来利用大江大河富余的水环境容量 ${ }^{[16]}$. 同时, 为了保证下游纳污水域的水质安 全, 可以采取以下 2 种措施: 1 ) 在受水区冲污出口处设置污水处理厂, 净化水体, 使之达到下游纳污水域的 水质标准后再排出; 2 ) 控制引水流量, 使得下游纳污水域不超过其水功能区水质目标, 引水流量上限可依据 《水域纳污能力计算规程》(GB/T 25173-2010) 计算得到.

\section{1 基于 DEM 的二维水量水质数学模型}

\section{1 基本控制方程}

1.1 .1 水动力模型 二维非恒定浅水运动方程为:

$$
\frac{\partial h}{\partial t}+\frac{\partial(h u)}{\partial x}+\frac{\partial(h v)}{\partial y}=q
$$




$$
\begin{gathered}
\frac{\partial(h u)}{\partial t}+u \frac{\partial(h u)}{\partial x}+v \frac{\partial(h u)}{\partial y}=f h v-g \frac{\partial h^{2}}{\partial x}-g h \frac{\partial z}{\partial x}-g n^{2} \frac{u \sqrt{u^{2}+v^{2}}}{h^{1 / 3}}+ \\
\frac{\partial}{\partial x}\left(\varepsilon_{x} h \frac{\partial u}{\partial x}\right)+\frac{\partial}{\partial y}\left(\varepsilon_{x} h \frac{\partial u}{\partial y}\right)+\frac{C_{\mathrm{a}} \rho_{\mathrm{a}} W_{x}\left(W_{x}^{2}+W_{y}^{2}\right)^{1 / 2}}{\rho} \\
\frac{\partial(h v)}{\partial t}+u \frac{\partial(h v)}{\partial x}+v \frac{\partial(h v)}{\partial y}=-f h u-g \frac{\partial h^{2}}{\partial y}-g h \frac{\partial z}{\partial y}-g n^{2} \frac{v \sqrt{u^{2}+v^{2}}}{h^{1 / 3}}+ \\
\frac{\partial}{\partial x}\left(\varepsilon_{y} h \frac{\partial v}{\partial x}\right)+\frac{\partial}{\partial y}\left(\varepsilon_{y} h \frac{\partial v}{\partial y}\right)+\frac{C_{\mathrm{a}} \rho_{\mathrm{a}} W_{y}\left(W_{x}^{2}+W_{y}^{2}\right)^{1 / 2}}{\rho}
\end{gathered}
$$

式中, $x 、 y$ 分别为湖水纵向、横向的流动距离, $t$ 为时间, $q$ 为湖泊的区间人流, $u 、 v$ 分别为 $x 、 y$ 方向的流速, $h$ 为水深, $z$ 为水位, $g$ 为重力系数, $f$ 为柯氏力常数, $n$ 为糙率, $C_{\mathrm{a}}$ 为风阻力系数, $\rho$ 、 $\rho_{\mathrm{a}}$ 分别为水和空气的密度, $\varepsilon_{x} 、 \varepsilon_{y}$ 分别为 $x 、 y$ 方向的浴动粘滞系数, $W_{x} 、 W_{y}$ 分别为 $x 、 y$ 方向上的风速.

1.1.2 非持久性污染物迁移转化方程 根据质量平衡原理, 平面二维水质迁移转换基本方程为:

$$
\frac{\partial(h c)}{\partial t}+u \frac{\partial(h c)}{\partial x}+v \frac{\partial(h c)}{\partial y}=\frac{\partial}{\partial x}\left(E_{x} \frac{\partial(h c)}{\partial x}\right)+\frac{\partial}{\partial y}\left(E_{y} \frac{\partial(h c)}{\partial y}\right)+h \sum S_{i}
$$

式中, $c$ 为湖泊水体中某种污染物的浓度, $E_{x} 、 E_{y}$ 分别为 $x 、 y$ 方向的分子扩散系数、紊动扩散系数和离散系数 之和, $\sum S_{i}$ 为湖泊水体污染物的源汇项, 其他符号意义与水运动方程相同.

\section{2 方程的离散}

对于水动力模型和非持久性污染物迁移转化模型, 采用有限体积法离散. 有限体积法导出的离散方程 可以保证具有守恒特性, 而且离散方程系数的物理意义明确, 具有很大的灵活性, 是目前水质模拟问题的数 值计算中应用较好的一种方法 ${ }^{[17]}$.

\section{3 水深修正}

DEM 网格的水深修正与同位网格类似,采用解压力耦合方程的半隐式法 (SIMPLEC) 和压力加权插值方 法 (PWIM) 水深修正公式. SIMPLEC 法是 SIMPLE 算法的一种修正方案, 改进了 SIMPLE 算法中忽略邻点速 度修正影响的简化处理,研究表明,在密网格下 SIMPLEC 算法的收玫性更好 ${ }^{[18]}$.

\section{4 初边条件}

在水陆边界上, 法向流速为 0 , 并且切向流速满足 $\partial \phi / \partial \tau=0$ 或 $\partial \phi / \partial \eta=0$; 在人流边界上, 给定流量变化 过程; 在出流边界上, 给定水位变化过程; 在计算的初始时刻, $u=0, v=0, z$ 由实测数据内插得到.

\section{5 动边界问题}

本模型采用干湿法处理动边界问题, 定义如果计算点的水深 $h$ 小于 0 , 则该格点为无效格点, 并且把该 格点上的水量流到相邻的边界格点上, 以保证水量平衡, 然后重新生成边界. 如果该无效格点的高程 $h_{b}$ 小于 相邻边界格点的水位 $z$, 则认为水流将流人该无效格点, 并从其相邻的边界格点中减去流到该点的水量, 然 后重新生成边界.

\section{6 方程组的求解}

本模型主要采用交替方向隐式迭代算法 (ADI) 和三对角矩阵直接算法 (TDMA) 联合求解方程组 ${ }^{[19]}$.

\section{2 成本和效益评估方法}

本文考虑引水冲污时下游纳污水域的水质安全, 控制引水流量在一定范围内,保证下游纳污水域不会 超过其水质目标, 此时无需投人资金用以改善水质,认为下游纳污水域无经济损失. 引水流量上限依据《水 域纳污能力计算规程》( GB/T 25173-2010) 计算得到.

本文中的经济效益是指由于引水调控的作用, 湖泊内部分污染物转移到下游纳污水域, 使得湖泊污水 处理费用减少所带来的效益. 基于前文所述水动力和迁移转化模型计算的流场和浓度场,经济效益可通过 公式(5)进行计算:

$$
E_{\mathrm{a}}=P_{\mathrm{a}}\left(M_{0}-M_{1}\right)
$$


式中, $E_{\mathrm{a}}$ 是经济效益 $(\mathrm{RMB}) ; M_{0}$ 是初始污染物 $(\mathrm{g})$, 即引水前湖泊中的污染物量, 根据湖泊中的某典型污染 物浓度场计算得出, 该典型污染物可根据湖泊的实际情况选定为化学需氧量 $\left(\mathrm{COD}_{\mathrm{Cr}}\right)$ 、总磷 $(\mathrm{TP})$ 和氨氮 $\left(\mathrm{NH}_{3}-\mathrm{N}\right) ; M_{1}$ 是引水后污染物 $(\mathrm{g})$, 即引水调控后湖泊中的污染物量, 由二维水量水质数学模型模拟得到; $P_{\mathrm{a}}$ 是处理 $1 \mathrm{~g}$ 污染物的成本 $(R M B / g) . P_{\mathrm{a}}$ 可以通过公式 $(6)$ 进行计算:

$$
P_{\mathrm{a}}=P_{\mathrm{w}} / C_{\mathrm{n}}
$$

式中, $P_{w}$ 是当地每立方水的水价中包含的污染物处理费 $\left(\mathrm{RMB} / \mathrm{m}^{3}\right)$, 通常可以当做该地区污染物治理的费 用标准; $C_{\mathrm{n}}$ 是每立方水经生产生活使用后含有的污染物浓度 $\left(\mathrm{g} / \mathrm{m}^{3}\right)$.

为评估江湖连通方案的最佳引水流量, 还需考虑连通工程的成本. 在本文中, 不考虑水体连通工程的建 设成本,仅考虑其运行成本. 因此,运行成本主要为百站的运行费用,可通过式(7)计算:

$$
C_{\mathrm{p}}=P_{\mathrm{p}} Q T
$$

式中, $C_{\mathrm{p}}$ 是运行成本 $(\mathrm{RMB}), P_{\mathrm{p}}$ 是泵站运行费 $\left(\mathrm{RMB} / \mathrm{m}^{3}\right), Q$ 是连通工程的引水流量 $\left(\mathrm{m}^{3} / \mathrm{s}\right), T$ 是冲污时间 (s).

工程净效益 $(E)$ 为经济效益与运行成本之差, 公式为:

$$
E=E_{\mathrm{a}}-C_{\mathrm{p}}
$$

\section{3 模型与方法应用}

\section{1 研究区域}

3.1.1 磁湖水污染现状及其成因 磁湖流域 $\left(29^{\circ} 40^{\prime} \sim 30^{\circ} 15^{\prime} \mathrm{N}, 114^{\circ} 31^{\prime} \sim 115^{\circ} 02^{\prime} \mathrm{E}\right)$ 包括磁湖、青山湖和青 港湖, 位于湖北省东南部、长江中游南岸的黄石市区内. 流域地处幕阜山系北侧江南丘陵带, 南依黄荆山脉, 东北临长江,三面群山环抱,位于市中心而形成盆地地带.

表 $12007-2011$ 年磁湖水质指标年际变化

Tab. 1 Annual variation of water quality parameters in Lake Cihu during 2007-2011

\begin{tabular}{ccccc}
\hline & & $\begin{array}{c}\mathrm{TP} / \\
(\mathrm{mg} / \mathrm{L})\end{array}$ & $\begin{array}{c}\mathrm{TN} / \\
(\mathrm{mg} / \mathrm{L})\end{array}$ & $\begin{array}{c}\mathrm{COD}_{\mathrm{Cr}} / \\
(\mathrm{mg} / \mathrm{L})\end{array}$ \\
\hline 年份 & 2007 & 0.24 & 2.96 & 32.09 \\
& 2008 & 0.18 & 2.78 & 25.90 \\
& 2009 & 0.17 & 2.34 & 24.29 \\
& 2010 & 0.17 & 2.48 & 25.71 \\
& 2011 & 0.13 & 1.81 & 22.10 \\
水质标准 & III类 & $\leqslant 0.05$ & $\leqslant 1$ & $\leqslant 20$ \\
& IV 类 & $\leqslant 0.1$ & $\leqslant 1.5$ & $\leqslant 30$ \\
V 类 & $\leqslant 0.2$ & $\leqslant 2$ & $\leqslant 40$ \\
\hline
\end{tabular}

泊富营养化中具有一定的代表性 ${ }^{[20]}$.
磁湖是磁湖流域最大的湖泊, 湖面面积约 $8.0 \mathrm{~km}^{2}$, 汇水 面积 $62.19 \mathrm{~km}^{2}$, 平均水深 $1.75 \mathrm{~m}$, 湖水经胜阳港闸与长江连 通. 磁湖是以城市景观和生态调节为主要功能的湖泊, 按照 黄石市政府批准的《黄石市水功能区划报告》, 磁湖作为景 观娱乐用水区 ${ }^{[21]}$, 应执行《地表水环境质量标准》 (GB/T 3838-2002) 所规定的 III 类水质标准. 目前, 磁湖水 污染严重,生态状况日渐恶化, 从近 5 年实测的各类水质指 标统计结果来看 (表 1$)^{[22]}$, 磁湖水体水质均为 $\mathrm{V}$ 类水. 导致 磁湖水污染严重的成因可大致概括为 4 个方面: 磁湖水流运 动系风生湖流型, 其水流缓慢、动力掺混能力弱; 治水工程的 实施导致江湖隔断, 使得污染物不易向外湖转移; 长期承受 磁湖周边的工厂和居民的大量工业废水和生活污水, 其人湖 污染负荷量大, 远超过磁湖的自净能力 ${ }^{[23]}$; 磁湖周边的菜地 种植和养殖排人的大量有机污染物 ${ }^{[24]}$. 这种情况在城市湖

3.1 .2 磁湖水体连通方案 针对磁湖严重的水污染问题及其成因, 并考虑到磁湖毗邻的长江段水质良好, 可 以沿用“引江济太”的策略,引长江水入磁湖, 以达到改善磁湖水质的目的.

引江人湖治理工程的原理是采用人工方式将清洁的江水引人内湖, 通过稀释降低湖泊水体中的 COD 等 主要污染物浓度, 增加水的循环、缩短水的换水周期, 达到改善湖泊水质的目的. 除此之外, 水体流动还可以 增加水体中的溶解氧, 有利于污染物的降解和矿化, 同时促进湖泊的水力交换、加快污染物的扩散速度, 使 得湖区水质趋于均匀化,有利于提高湖泊的整体自净能力.

通过比选, 磁湖水体连通采用水体置换式, 即引城市上游优质长江水进入磁湖置换原有水体. 引水路线 
如图 1 所示, 具体引水方案如下: 在距离黄石长江干堤桩 57 号 $500 \mathrm{~m}$ 处新建青山湖提水泵站, 水流经 $2.04 \mathrm{~km}$ 青山湖湖底箱涵直接人青山湖 1 号湖——副湖, 以副湖为前池, 水流将分两路分别进入青山湖及青 港湖. 一路进入青山湖, 经青山湖排涝百站抽排入江; 另一路经盘龙山隧洞进人青港湖, 以青港湖为前池水 流分两路分别进人磁湖,一路经青港湖生态港渠、王家桥生态港渠进人北磁湖, 另一路则通过青港湖生态港 渠、磁湖提水葲站、大泉路输水箱涵及现有市政排水箱涵(大泉路、杭州西路、青鱼路)进人南磁湖,最后经胜 阳岗闸自排人江.

在磁湖水体连通方案中, 充分利用了长江特定段的富余水环境容量, 即将景观娱乐用水区的水体 (磁 湖, 控制目标为 III类水) 排人排污控制区 (长江冶钢取水口 西塞山段, 无控制目标; 下游紧邻水域为过渡 区, 其控制目标为 III 类水), 并不影响长江水体达标. 为了达到基本冲污效果, 并尽量节约投资和运行费用, 本文将在此引水路线基础上研究连通方案的最佳引水流量.

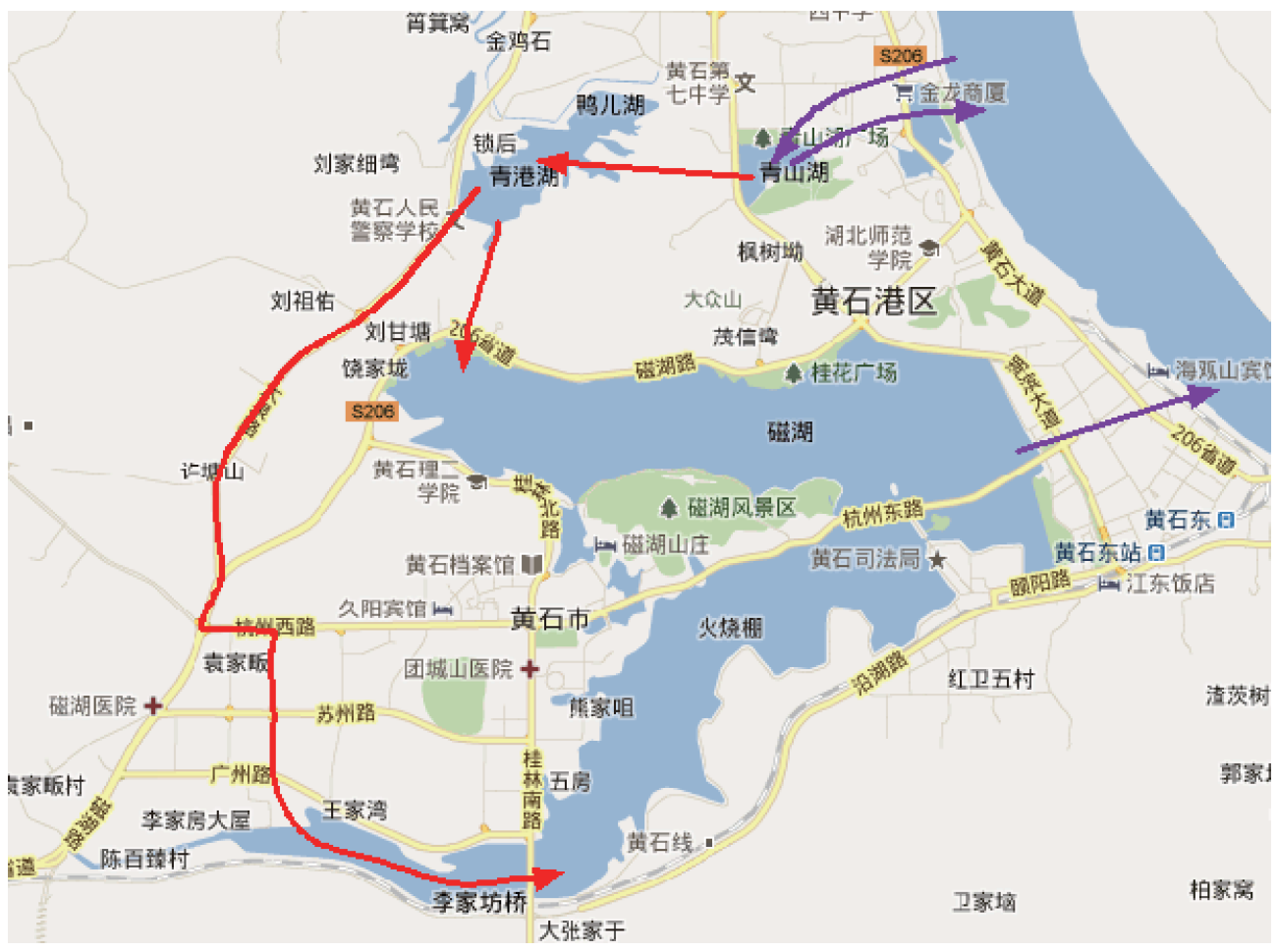

图 1 磁湖水体连通路线

Fig. 1 Path of interconnected river system network of Lake Cihu

\section{2 计算和预测范围}

选取磁湖为计算范围的起始断面,包括南半湖和北半湖,根据已有的磁湖武汉关至白浒段水下地形图, 利用 ArcGIS 工具生成 DEM 数据. 计算区域 DEM 空间步长纵向距离 $\Delta X=5.0 \mathrm{~m}$, 横向距离 $\Delta Y=5.0 \mathrm{~m}$,网格 总数为 $1064 \times 923$ 个,有效计算格点总数为 348071 个. 水下地形及部分计算网格见图 2 .

\section{3 参数率定和模型验证}

磁湖属于宽浅型湖泊, 水流运动主要受到湖面风场影响, 以风生场为主. 根据气象局资料, 黄石市地处 中纬度, 远离海洋, 属亚热带湿润季风气候, 境内多东南风. 因为与长江连通的胜阳港闸只是在汛期短期开 闸,故磁湖的现状计算仅考虑由风驱动形成的风生流场, 其风速取黄石市多年平均值 $(2.17 \mathrm{~m} / \mathrm{s})$, 风向取风 向频率最高的东南风. 运用前面所介绍的基于 DEM 的二维水量水质模型进行数学描述, 结合现有的资料, 选取 $\mathrm{COD}_{\mathrm{Cr}}$ 为水质指标.

本文所建模型中的参数主要包括柯氏力常数、风阻力系数、樯率、浴动粘滞系数、扩散系数和 COD 降解 


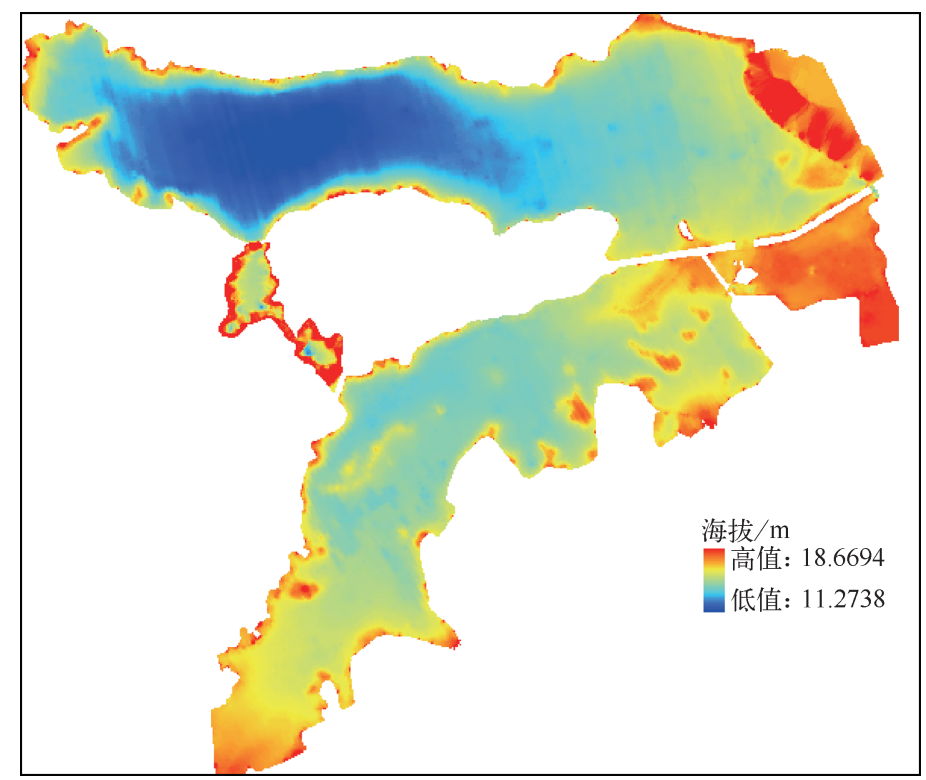

图 2 磁湖南、北半湖 DEM 地形图

Fig. 2 DEM topographic map of the northern and southern Lake Cihu

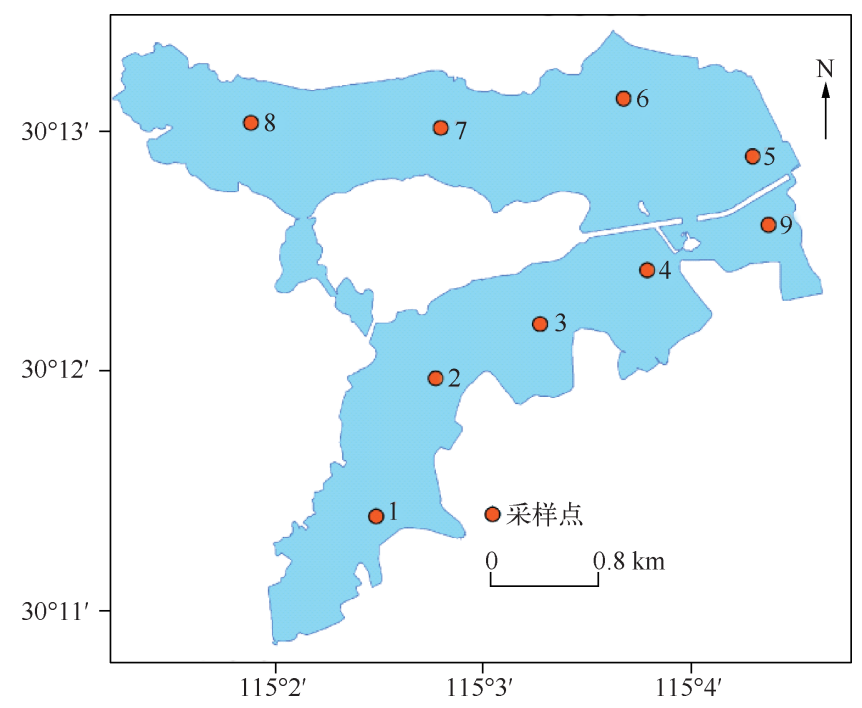

图 3 磁湖采样点位置示意

系数. 柯氏力常数的确定采用公式 $f=$ $2 \Omega \sin \varphi$ 计算 (式中, $\varphi$ 为研究区域的纬 度, 取 $30^{\circ} ; \Omega$ 为地转角速度, 约为 $2 \pi /$ $\left.(24 \times 3600) \mathrm{s}^{-1}\right)$. 风阻力系数根据经验 公式 $C_{\mathrm{a}}=10^{-3}\left(1.1+0.0536 W_{\mathrm{a}}\right)$ 计算 得到 ${ }^{[25]}$, 式中, $W_{\mathrm{a}}$ 为湖面以上 $10 \mathrm{~m}$ 处 的平均风速, 为 $2.17 \mathrm{~m} / \mathrm{s}$. 糙率、涡动粘 滞系数、扩散系数和 COD 降解系数采 用试算率定,选择 2011 年 4 月 8 日至 7 月 16 日作为模型的参数率定计算时 段, 根据汉口水文站监测的同日期的流 量、水位资料和磁湖的 9 个采样点 (位 置见图 3 ) 的水质参数资料, 对水流和 水质模型进行参数率定, 使模型计算值 与实测值达到总体最优, 其模型参数值 见表 2 .

Fig. 3 Location of sampling sites in Lake Cihu

表 2 磁湖水环境模型参数率定成果

Tab. 2 Parameters confirmed in water quality model of Lake Cihu

\begin{tabular}{cccc}
\hline 参数 & 数值 & 参数名称 & 数值 \\
\hline 柯氏力常数 & $7.27 \times 10^{-5} \mathrm{~s}^{-1}$ & 风阻力系数 & 0.0012 \\
糙率 & 0.01 & $\mathrm{COD}_{\mathrm{Cr}}$ 降解系数 & $0.15 \mathrm{~d}^{-1}$ \\
横向浴动粘滞系数 & $8.90 \mathrm{~m}^{2} / \mathrm{s}$ & 横向扩散系数 & $0.50 \mathrm{~m}^{2} / \mathrm{s}$ \\
纵向浴动粘滞系数 & $8.90 \mathrm{~m}^{2} / \mathrm{s}$ & 纵向扩散系数 & $0.80 \mathrm{~m}^{2} / \mathrm{s}$ \\
\hline
\end{tabular}


选用 2011 年 8 月 8 日至 10 月 9 日的实测水质数据对模型进行验证, 以 2011 年 8 月 8 日的 $\mathrm{COD}_{\mathrm{Cr}}$ 浓度 作为初始浓度,采用模型模拟到 9 月 24 日和 10 月 9 日,模拟水质结果分别与这两天的实测浓度进行对比. 对比验证结果可知, 模拟值与实测值非常接近, 相对误差大多数小于 $15 \%$ (表 3 ), 表明二维水量水质数学模 型及其关键参数能用来较好的模拟 $\mathrm{COD}_{\mathrm{Cr}}$ 指标.

表 3 磁湖水环境模型验证成果

Tab. 3 Results of water quality model validation in Lake Cihu

\begin{tabular}{|c|c|c|c|c|c|c|}
\hline \multirow{2}{*}{ 采样点 } & \multicolumn{3}{|c|}{9 月 24 日 } & \multicolumn{3}{|c|}{10 月 9 日 } \\
\hline & 实测值 $/(\mathrm{mg} / \mathrm{L})$ & 模拟值 $/(\mathrm{mg} / \mathrm{L})$ & 误差/\% & 实测值 $/(\mathrm{mg} / \mathrm{L})$ & 模拟值/(mg/L) & 误差/\% \\
\hline $1^{\#}$ & 19.4 & 17.7 & 9 & 19.1 & 18.7 & 2 \\
\hline $2^{\#}$ & 16.4 & 17.3 & 5 & 19.6 & 19.2 & 2 \\
\hline $3^{\#}$ & 16.0 & 16.4 & 2 & 19.8 & 16.8 & 15 \\
\hline $4^{\#}$ & 17.3 & 24.3 & 40 & 19.5 & 22.5 & 15 \\
\hline $5^{\#}$ & 18.3 & 14.1 & 23 & 21.0 & 16.8 & 20 \\
\hline $6^{\#}$ & 13.2 & 13.1 & 1 & 17.6 & 14.7 & 16 \\
\hline $7^{\#}$ & 14.9 & 13.9 & 7 & 22.0 & 20.3 & 8 \\
\hline $8^{\#}$ & 16.0 & 16.9 & 6 & 21.7 & 19.7 & 9 \\
\hline $9^{\#}$ & 16.4 & 14.6 & 11 & 21.1 & 16.7 & 21 \\
\hline
\end{tabular}

\section{4 初边条件}

依据《湖北省水功能区划》, 经胜阳港闸与磁湖连通的长江段 (冶钢取水口一西塞山段) 的水功能区是 排污控制区,下游与其相邻的是过渡区, 水质目标为 III 类水,即需保证排污控制区的出流断面水质要达到 III 类标准. 在水体连通工程的可行性研究报告 ${ }^{[26]}$ 中, 为了保证引水调控时下游接纳污染水域的水质安全、满足 水功能区水质目标, 依据《水域纳污能力计算规程》( GB/T 25173-2010) 的相关规定, 建议磁湖水体连通方 案的引水流量不超过 $16 \mathrm{~m}^{3} / \mathrm{s}$.

本文为了分析不同引水流量的水质改善效果,制定了 8 种不同引水流量计算工况(表 4). 给定计算初始 水位和污染物指标浓度, 根据 9 个水质监测点 2011 年实测水质数据的年平均值 $\left(1^{\#} \sim 9^{\#}\right.$ 样点 $\mathrm{COD}_{\mathrm{Cr}}$ 浓度分 别为 $25.8 、 29.1 、 25.3 、 26.8 、 21.6 、 20.0 、 20.9 、 20.6 、 21.9 \mathrm{mg} / \mathrm{L})$, 利用 ArcGIS 工具插值生成初始浓度. 水流 人边界上, 由于长江实测水质数据资料有限,参照湖北省黄石市环境检测局 $2001-2005$ 年磁湖毗邻长江段 的水质监测数据 ${ }^{[23]}$, 生化需氧量、总磷、总氮等指标 5 年的平均浓度都小于相应的地表水 II 类水标准限值, 故选定引水的水质浓度为 II 类水标准. 此外,水流出边界上,水位控制在磁湖正常蓄水位 $(16.83 \mathrm{~m})$.

\section{表 4 计算工况表}

Tab. 4 Working conditions of calculation

\begin{tabular}{|c|c|c|c|c|}
\hline 工况编号 & 时间 & 引水流量 $/\left(\mathrm{m}^{3} / \mathrm{s}\right)$ & 引水 $\mathrm{COD}_{\mathrm{Cr}}$ 浓度/ $(\mathrm{mg} / \mathrm{L})$ & 说明 \\
\hline 1 & 现状 & 0 & 0 & 风生场 \\
\hline 2 & 远期 & 4 & 15 & 风生场、连通方式 \\
\hline 3 & 远期 & 6 & 15 & 风生场、连通方式 \\
\hline 4 & 远期 & 8 & 15 & 风生场、连通方式 \\
\hline 5 & 远期 & 10 & 15 & 风生场、连通方式 \\
\hline 6 & 远期 & 12 & 15 & 风生场、连通方式 \\
\hline 7 & 远期 & 14 & 15 & 风生场、连通方式 \\
\hline 8 & 远期 & 16 & 15 & 风生场、连通方式 \\
\hline
\end{tabular}

\section{5 模拟预测结果与分析}

根据上述的计算条件和现有资料,得到 8 种计算工况的模拟结果, 见表 5 .

3.5.1 $\mathrm{COD}_{\mathrm{Cr}}$ 浓度随引水时间变化 引水对改善 $\mathrm{COD}_{\mathrm{Cr}}$ 浓度的效果十分显著,引水前水质较差的磁湖中超标 
水体面积高达 $82.47 \%$,引水 $7 \mathrm{~d}$ 后, 在各工况下, 磁湖的 IV 、V 类水体面积都有不同程度的下降, 变化为 III 类 水, 至 $15 \mathrm{~d}$, 分布变化情况基本稳定, 这表明 $\mathrm{COD}_{\mathrm{Cr}}$ 浓度的变化逐渐趋近动态平衡状态, 引水时间越长对减小 $\mathrm{COD}_{\mathrm{Cr}_{\mathrm{r}}}$ 浓度的贡献将越小,这时磁湖中 $40 \%$ 左右的水体 $\mathrm{COD}_{\mathrm{cr}}$ 浓度能够达到 III 类水质标准.

表 5 各工况引水不同时间后 $\mathrm{COD}_{\mathrm{Cr}}$ 情况

Tab. 5 Distribution of $\mathrm{COD}_{\mathrm{Cr}}$ under different working conditions after flushing different days

\begin{tabular}{|c|c|c|c|c|c|c|}
\hline \multirow{2}{*}{ 引水时间 } & \multirow{2}{*}{ 工况编号 } & \multirow{2}{*}{$\begin{array}{c}\text { 超标水体 } \\
\text { 面积比例/\% }\end{array}$} & \multicolumn{4}{|c|}{ 浓度分布比例/\% } \\
\hline & & & III类 & IV类 & $\mathrm{V}$ 类 & 劣 $V$ 类 \\
\hline \multirow[t]{8}{*}{$1 \mathrm{~d}$} & 1 & 82.47 & 17.53 & 67.54 & 10.81 & 4.12 \\
\hline & 2 & 77.34 & 22.66 & 64.94 & 8.73 & 3.67 \\
\hline & 3 & 77.16 & 22.84 & 64.98 & 8.56 & 3.62 \\
\hline & 4 & 77.04 & 22.96 & 65.05 & 8.42 & 3.57 \\
\hline & 5 & 76.82 & 23.18 & 65.01 & 8.28 & 3.53 \\
\hline & 6 & 76.59 & 23.41 & 64.97 & 8.15 & 3.47 \\
\hline & 7 & 75.41 & 24.59 & 63.95 & 8.02 & 3.44 \\
\hline & 8 & 74.88 & 25.12 & 63.58 & 7.92 & 3.38 \\
\hline \multirow[t]{8}{*}{$7 \mathrm{~d}$} & 1 & 82.47 & 17.53 & 67.54 & 10.81 & 4.12 \\
\hline & 2 & 66.06 & 33.94 & 56.63 & 5.84 & 3.59 \\
\hline & 3 & 63.99 & 36.01 & 55.34 & 5.18 & 3.47 \\
\hline & 4 & 61.84 & 40.16 & 54.00 & 4.49 & 3.35 \\
\hline & 5 & 59.95 & 40.05 & 52.71 & 3.98 & 3.26 \\
\hline & 6 & 58.02 & 41.98 & 51.35 & 3.53 & 3.14 \\
\hline & 7 & 57.08 & 42.92 & 51.09 & 2.98 & 3.01 \\
\hline & 8 & 56.11 & 43.89 & 50.56 & 2.59 & 2.96 \\
\hline \multirow[t]{8}{*}{$15 \mathrm{~d}$} & 1 & 82.47 & 17.53 & 67.54 & 10.81 & 4. 12 \\
\hline & 2 & 64.14 & 35.86 & 55.31 & 4.98 & 3.85 \\
\hline & 3 & 62.17 & 37.83 & 54.32 & 4.26 & 3.59 \\
\hline & 4 & 60.23 & 39.77 & 53.16 & 3.60 & 3.47 \\
\hline & 5 & 58.15 & 41.85 & 51.68 & 3.12 & 3.35 \\
\hline & 6 & 56.20 & 43.80 & 50.35 & 2.69 & 3.16 \\
\hline & 7 & 53.37 & 46.63 & 47.92 & 2.34 & 3.11 \\
\hline & 8 & 50.54 & 49.46 & 45.53 & 2.10 & 2.91 \\
\hline \multirow[t]{8}{*}{$23 \mathrm{~d}$} & 1 & 82.47 & 17.53 & 67.54 & 10.81 & 4. 12 \\
\hline & 2 & 61.93 & 38.07 & 52.76 & 5.27 & 3.90 \\
\hline & 3 & 60.12 & 39.88 & 51.83 & 4.52 & 3.77 \\
\hline & 4 & 58.24 & 41.76 & 50.94 & 3.75 & 3.55 \\
\hline & 5 & 56.57 & 43.43 & 49.86 & 3.28 & 3.44 \\
\hline & 6 & 54.91 & 45.09 & 48.94 & 2.75 & 3.22 \\
\hline & 7 & 51.44 & 48.56 & 45.93 & 2.46 & 3.05 \\
\hline & 8 & 47.76 & 52.24 & 42.64 & 2.18 & 2.94 \\
\hline
\end{tabular}

3.5.2 $\mathrm{COD}_{\mathrm{Cr}}$ 浓度随引水流量变化 引水 $1 、 7 、 15 、 23 \mathrm{~d}$ 的模拟结果中, 各工况下磁湖的超标水体比例均随着 引水流量增加而减少, 且效果明显, 但增加幅度逐步下降, 引水 $15 \mathrm{~d}$ 后, 超标水体面积在引水流量为 $4 \mathrm{~m}^{3} / \mathrm{s}$ 的工况 2 下为 $64.14 \%$, 而在引水流量为 $16 \mathrm{~m}^{3} / \mathrm{s}$ 的工况 8 下为 $50.54 \%$.

\section{6 最佳引水流量分析}

通过对 $\mathrm{COD}_{\mathrm{Cr}}$ 浓度随着引水时间和引水流量的变化和分布变化分析, 表明在引水 $15 \mathrm{~d}$ 后各种工况下, 磁湖 $\mathrm{COD}_{\mathrm{Cr}}$ 平均浓度大小和浓度分布都基本达到稳定. 为了评估引水冲污产生的效益, 针对表 5 各种工况引 水 $15 \mathrm{~d}$ 后的计算结果, 表 6 列出了几个关键的指标. 其中, “初始污染物” 是指引水冲污前磁湖水体中的 COD 污染物总量, “引水后污染物”是指引水冲污后磁湖水体中的 COD 污染物总量.

计算过程中,依据原国家环境保护总局颁发的环发 [2003]141 号文件 ${ }^{[27]}$ 和《湖北省用水定额》的相关规 定, 可以估算得到黄石市的生活污水 $\mathrm{COD}_{\mathrm{Cr}}$ 浓度约为 $300 \mathrm{mg} / \mathrm{L}$. 黄石市的排污处理费为每立方水 0.8 元. 由 
于应用于本工程的青山湖提水洜站还在规划中,所以本文参考黄石市境内 3 座已投人使用的葲站及它们每 年需要的电费和维修养护经费,估算得到泵抽水的价格 $P_{\mathrm{p}}$ 为每立方水 0.01 元. 然后可以利用公式 $(5) \sim$ (8) 计算得出相关的指标.

表 6 各工况引水冲污的效益与花费

Tab. 6 Investments and benefits under different working conditions

\begin{tabular}{ccccccc}
\hline $\begin{array}{c}\text { 引水流量/ } \\
\left(\mathrm{m}^{3} / \mathrm{s}\right)\end{array}$ & $\begin{array}{c}\text { 水量/ } \\
\left(\times 10^{6} \mathrm{~m}^{3}\right)\end{array}$ & $\begin{array}{c}\text { 初始污染物/ } \\
\left(\times 10^{8} \mathrm{~g}\right)\end{array}$ & $\begin{array}{c}\text { 引水后污染物/ } \\
\left(\times 10^{8} \mathrm{~g}\right)\end{array}$ & $\begin{array}{c}\text { 经济效益/ } \\
\text { 万元 }\end{array}$ & $\begin{array}{c}\text { 运行成本/ } \\
\text { 万元 }\end{array}$ & $\begin{array}{c}\text { 净效益/ } \\
\text { 万元 }\end{array}$ \\
\hline 4 & 5.18 & 6.26 & 6.03 & 7.61 & 5.18 & 2.43 \\
6 & 7.78 & 6.26 & 5.93 & 11.05 & 7.78 & 3.27 \\
8 & 10.40 & 6.26 & 5.83 & 14.21 & 10.37 & 3.84 \\
10 & 13.00 & 6.26 & 5.75 & 17.01 & 12.96 & 4.05 \\
12 & 15.60 & 6.26 & 5.67 & 19.51 & 15.55 & 3.96 \\
14 & 18.10 & 6.26 & 5.60 & 21.79 & 18.14 & 3.65 \\
16 & 20.70 & 6.26 & 5.54 & 23.74 & 20.74 & 3.00 \\
\hline
\end{tabular}

比较不同引水流量的成本和效益表明, 随着引水流量的增加, 经济效益呈现出先快 后慢的增长 (图 4), 这是因为湖泊湾、汊中的 水体难以得到置换, 对引水流量的增加不敏 感, 从而导致引水效率下降. 另一方面, 运行 成本则按照线性增加, 所以净效益先增大后 减小,可用开口向下的抛物线拟合. 为了进一 步分析结果,使用公式 $(9)$ 来拟合净效益 $(E)$ 随着引水流量 $(Q)$ 的变化:

$$
E=-0.037 Q^{2}+0.786 Q-0.126
$$

式(9) 所拟合的抛物线的决定系数为 0.9989 , 可以较好地反映出净效益随引水流量 增大的变化情况. 当引水流量为 $10.62 \mathrm{~m}^{3} / \mathrm{s}$ 时,净效益最大, 为 4.05 万元; 当引水流量为

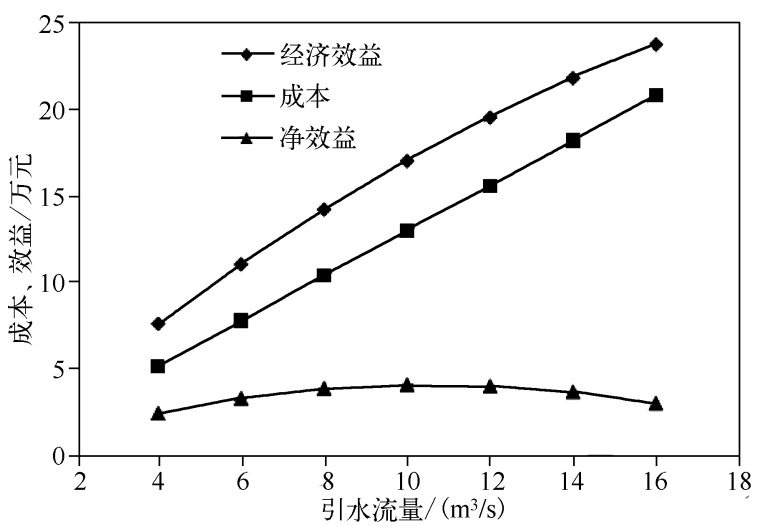

图 4 花费和收益与引水流量关系

Fig. 4 Quantitative relationship between flushing discharge and net benefit

$0.16 \mathrm{~m}^{3} / \mathrm{s}$ 或 $21.08 \mathrm{~m}^{3} / \mathrm{s}$ 时, 净效益为 0 元, 即净效益为正时的引水流量为 $0.16 \sim 21.08 \mathrm{~m}^{3} / \mathrm{s}$. 但考虑到要 满足下游纳污水域的水功能区水质目标, 因此, 引水流量的合理范围是 $0.16 \sim 16.00 \mathrm{~m}^{3} / \mathrm{s}$, 并且最佳引水流 量为 $10.62 \mathrm{~m}^{3} / \mathrm{s}$.

\section{4 结果与讨论}

1) 本文以磁湖为例, 通过对比分析磁湖水体连通方案中的 8 种不同引水流量对磁湖水质的改 善效果, 并定量计算出引水工程的经济效益和工程运行成本,得到磁湖的最佳引水流量为 10.62 $\mathrm{m}^{3} / \mathrm{s}$, 每次引水的最大净效益约为 4.05 万元. 最佳引水流量工况引水 $15 \mathrm{~d}$ 后 $\mathrm{COD}_{\mathrm{Cr}}$ 浓度和空间分布 结果显示, 在引水 $15 \mathrm{~d}$ 后磁湖水质基本达到稳定, 水质改善显著, 北半磁湖几乎都达到 III 类水质标准, 南半磁湖近 40\% 水体达到 III 类水质标准 (表 7 , 图 5 ), 也印证了引水工程是改善磁湖水环境的有效手 段之一.

2) 由于受到相关资料的限制, 本文只计算了 $\mathrm{COD}_{\mathrm{Cr}}$ 指标, 所以计算结果仅供参考,不作工程建设依据. 可以参考本文的数学模型和成本效益评估方法, 对其他水质指标进行模拟,例如 TP、TN 等,得到相应指标的 最佳引水流量, 然后对各指标进行综合分析, 得到磁湖的最佳引水流量. 
表 7 最佳引水流量工况引水 $15 \mathrm{~d}$ 后 $\mathrm{COD}_{\mathrm{Cr}}$ 情况

Tab. 7 Distribution of $\mathrm{COD}_{\mathrm{Cr}}$ under working condition with optimal flushing discharge after flushing 15 days

\begin{tabular}{cccccc}
\hline \multirow{2}{*}{$\begin{array}{c}\text { 最佳引水流量/ } \\
\left(\mathrm{m}^{3} / \mathrm{s}\right)\end{array}$} & $\begin{array}{c}\text { 超标水体面积比例 } \\
\%\end{array}$ & & \multicolumn{3}{c}{$\mathrm{COD}_{\mathrm{Cr}}$ 浓度分布比例 $/ \%$} \\
\cline { 3 - 6 } & 57.59 & III 类 & IV 类 & V类 & 劣 $\mathrm{V}$ 类 \\
\hline 10.62 & 42.41 & 51.32 & 3.00 & 3.27 \\
\hline
\end{tabular}

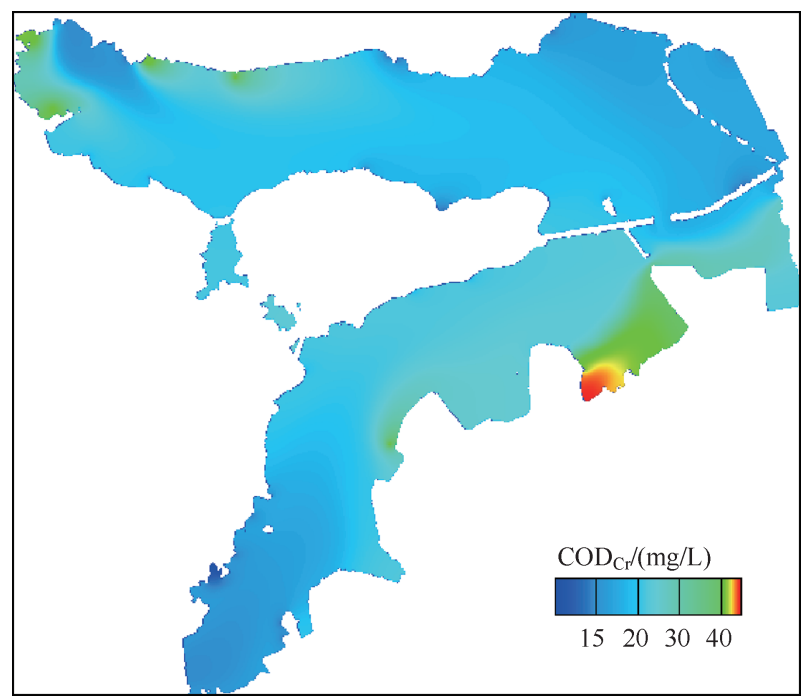

图 5 最佳引水流量工况引水 $15 \mathrm{~d}$ 后 $\mathrm{COD}_{\mathrm{Cr}}$ 浓度分布情况

Fig. 5 Spatial distribution of $\mathrm{COD}_{\mathrm{Cr}}$ concentration under working condition with optimal flushing discharge after flushing 15 days

3 ) 在保证下游纳污水域的水功能区水质目标的前提下, 通过水体连通使磁湖水质得到较为明显的改 善,但即使是引水流量为 $16 \mathrm{~m}^{3} / \mathrm{s}$ 的工况 8 (表 5 ), 磁湖的水质也难以 $100 \%$ 达到《地表水环境质量标准》 ( GB/T 3838-2002) 中所规定的磁湖应执行的 III类水质标准, 说明湖泊水质改善是一项综合工程, 不能寄希 望于单一的措施能够达到要求. 因此改善磁湖水质应综合治理、多管齐下,措施包括截污、清淤、生态治污和 引水工程等.

\section{5 参考文献}

[1] 秦伯强. 富营养化湖泊开敞水域水质净化的生态工程试验研究. 环境科学学报,2007,27(1):1-4.

[ 2 ] Diederik T, Van DM, Rob P et al. Changes in sediment phosphorus as a result of eutrophication and oligotrophication in Lake Veluwe, the Netherlands. Water Research,1998,32(11) : 3281-3288.

[3] 秦伯强,许 海,董百丽. 富营养化湖泊治理的理论与实践. 北京:高等教育出版社,2011:238-245.

[4] 朱政军,韩曾萃. 西湖引水淡化总磷浓度效果研究. 水力发电学报,2010,29(3):137-142.

[5] 马 巍, 廖文根, 李锦秀等. 引水调控改善太湖湖湾水环境及其效果预测. 长江流域资源与环境, 2007,16(1): $52-56$.

[6] 谢兴勇,钱 新,张玉超等.引江济巢对巢湖的水环境影响分析. 环境科学研究,2009,22(8):897-901.

[ 7 ] 甘升伟,张红举,冯﨎昀. 无锡水源地贡湖引水改善水质效果分析. 人民长江,2012,43(5):72-75.

[ 8 ] 罗佳翠,马 巍,禹雪中等. 滇池环境需水量及牛栏江引水效果预测. 中国农村水利水电,2010,(7):25-28.

[ 9 ] 王中根, 李宗礼, 刘昌明等. 河湖水系连通的理论探讨. 自然资源学报,2011,26(3):523-528.

[10］杨桐鹤, 禹雪中, 骆辉煌. 基于水污染损失模型的引水调控工程. 水利水电技术, 2010,41(9):20-27. 
[11] 梁 勇,陈升鬼, 闵庆文. 居民对改善城市环境支付意愿的研究. 水利学报,2005,36(5):1-7.

[12］李锦秀,徐嵩龄. 流域水污染经济损失计量模型. 水利学报,2003,(10):68-74.

[13] 阳书敏,邵东国,赵 丹等. 水利水电工程水环境效益分析与计算. 安全与环境学报, 2004,4(4):32-35.

[14] 吴浩云,周丹平,何 佳等. 引江济太工程综合效益的评估及方法探讨. 湖泊科学, 2008,20(5):639-647.

[15] 骆辉煌,禹雪中, 刘金鹏等. 引水调控工程经济效益评估初步框架. 中国水利水电科学研究院学报, 2009,7(1): $28-32$.

[16] 禹雪中,彭期冬. 引水调控改善生态环境的实践及趋势. 见: 中国水利学会 2005 年学术年会论文集. 北京: 中国水 利水电出版社, 2005:64-67.

[17] Zhang YJ, Roy G, Luo WS et al. A DEM-based parallel computing hydrodynamic and transport model. River Research and Applications, 2012, 28(5): 647-658.

[18] 张京兆, 屈治国, 何雅铃等. CLEAR 与 SIMPLE 系列的三种算法的收玫性和健壮性比较. 工程热物理学报, 2008,29 (12) :2111-2114.

[19] 帕坦卡. 传热与流体流热的数值计算. 北京:科学出版社, 1984: 70-77.

[20］彭俊杰,李传红,黄细花. 城市湖泊富营养化成因和特征. 生态科学,2004,23(4) :370-373.

[21] 尹传柏,徐学军,何子杰. 黄石市磁湖水力调度方案与效果分析. 人民长江, 2009,40(20):88-90.

[22] 尹耀锋. 城市小型湖泊水环境修复研究 [学位论文].武汉: 武汉大学, 2012.

[23] 伍静静,李登新,郑志雄等. 引江人湖修复城市内湖方案的初步探索. 环境科学与技术,2010,3(9):108-112.

[24] 张丽莉,赵旭德,胡亨鬼等. 磁湖污染现状调查与分析. 环境保护科学, 2008,(1):17-19.

[25］李畅游,史小红. 干旱半干旱地区湖泊二维水动力学模型. 水利学报,2007,38(12):1482-1488.

[26] 湖北省水利水电规划勘测设计院. 湖北省黄石市磁湖水生态系统保护与修复工程可行性研究设计报告. 2011.

[27] 张国峰.张 越. 生活污水中化学需氧量浓度. 见: 中国环境科学学会 2010 年学术年会论文集. 北京: 中国环境科 学出版社,2010: 3160-3162. 